\title{
Investigation of the Association of TLR2 and TLR4 Polymorphisms with Susceptibility to Helicobacter pylori-Related Gastrointestinal Diseases
}

Takayoshi Suzuki1 ${ }^{*}$, Akira Meguro², Masashi Matsushima1 ${ }^{1}$, Aya Masui ${ }^{1}$, Shingo Tsuda1, Jun Nakamura', Ryoko Nishina ${ }^{1}$, Tetsufumi Uchida ${ }^{1}$, Hiroki Yuhara ${ }^{1}$, Muneki Igarashi', Jun Koike1, Tetsuya Mine', Hidetoshi Inoko², Atsushi Takagi ${ }^{3}$

\footnotetext{
${ }^{1}$ Division of Gastroenterology \& Hepatology, Department of Internal Medicine, Tokai University School of Medicine, Isehara, Japan

${ }^{2}$ Division of Molecular Life Science, Department of Genetic Information, Tokai University School of Medicine, Isehara, Japan

${ }^{3}$ Division of General Internal Medicine, Department of Internal Medicine, Tokai University School of Medicine, Isehara, Japan

Email: ${ }^{*}$ takayosh@is.icc.u-tokai.ac.jp
}

Received 26 October 2014; revised 18 November 2014; accepted 15 December 2014

Copyright (C) 2014 by authors and Scientific Research Publishing Inc.

This work is licensed under the Creative Commons Attribution International License (CC BY).

http://creativecommons.org/licenses/by/4.0/

(c) (i) Open Access

\section{Abstract}

Background and Aim: Toll-like receptor (TLR) 2 and TLR4 are cell surface signaling receptors that are involved in the recognition of and host response to Helicobacter pylori. Our aim was to investigate the association between TLR gene polymorphisms and susceptibility of Japanese subjects to $4 \mathrm{H}$. pylori-related gastrointestinal diseases. Methodology: A total of 100 patients with histologically diagnosed gastric cancer, 105 patients with gastric ulcer, 102 with atrophic gastritis, 72 with duodenal ulcer and 428 healthy controls were recruited. A TaqMan assay was used to genotype 7 single nucleotide polymorphisms (SNPs) in TLR2 and 6 SNPs in TLR4. Results: There was a tendency for TLR4 rs10759932 TC/CC genotypes to be associated with a decreased risk of gastric cancer ( $p=0.059)$; however, this did not reach statistical significance. No significant associations were found between polymorphisms in TLR2 or TLR4 and the risks for gastric cancer, gastric ulcer, duodenal ulcer, or atrophic gastritis. Conclusion: The 13 SNPs inTLR2 and TLR4 examined in this study may not be linked with the development of $H$. pylori-related gastrointestinal diseases. Further studies with larger numbers of subjects are necessary to verify the present findings.

\footnotetext{
"Corresponding author.
}

How to cite this paper: Suzuki, T., et al. (2014) Investigation of the Association of TLR2 and TLR4 Polymorphisms with Susceptibility to Helicobacter pylori-Related Gastrointestinal Diseases. Open Journal of Internal Medicine, 4, 130-136. 


\section{Keywords}

\section{TLR2, TLR4, Polymorphisms, Helicobacter pylori}

\section{Introduction}

Helicobacter pylori is a spiral-shaped, microaerophilic, gram-negative bacterium that colonizes the human stomach and establishes persistent infection in the gastric mucosa. Numerous studies have also shown that $H$. pylo$r i$ is a risk factor for development of upper gastrointestinal diseases, such as peptic ulcer disease, atrophic gastritis, gastric mucosa-associated lymphatic tissue lymphoma and gastric cancer [1] [2]. Several studies have indicated that $H$. pylori infection is the best recognized etiologic risk factor for gastric cancer, the leading cause of cancer-related death worldwide [3], through its involvement in the development of gastric atrophy or precancerous lesions [4] [5]. However, only a small fraction of $H$. pylori-infected patients eventually develop gastric cancer; thus, in addition to bacterial virulence factors, genetic susceptibility, immune response and environmental factors may also play important roles in the clinical outcome of long-term $H$. pylori infection.

Toll-like receptors (TLRs) are proteins that play important roles in pattern recognition of various substances that are produced by microorganisms. To date, 10 different TLRs have been identified in humans [6]. Among these, TLR2 recognizes bacterial lipoproteins and peptioglycans that are produced by gram-positive bacteria, while TLR4 is the receptor for lipopolysaccharides of gram-negative bacteria.

TLR2 and TLR4 are expressed on several types of cells in many human tissues, and they act as important mediators of the inflammatory response in the first line of host defense against microbial infections. Amongst other cell types, these receptors are expressed on gastric epithelial cells and are involved in the recognition of $H$. pylo$r i$ and in the immunological response of the host to these bacteria [7]-[10]. Moreover, several studies have shown that the progression of precancerous lesions in the stomach is accompanied by increases in the expressions levels of these TLRs in gastric epithelial cells, suggesting that these receptors may play a role in development of adenocarcinoma in the gastric mucosa [11] [12].

Recent evidence has suggested that polymorphisms in genes encoding TLR are associated with several cancers, such as colorectal cancer, cervical cancer and gallbladder cancer [13]-[15]. Several reports have indicated that specific polymorphisms, such as the TLR2 -196 to -174 deletion, and the TLR4 polymorphisms rs49896790 and rs49896791, influence the susceptibility to gastric cancer [16]-[18]. However, little information is available regarding the association between other polymorphisms in TLR2 or TLR4 and H. pylori-related gastrointestinal diseases. The aim of this study was to investigate associations between 7 single nucleotide polymorphisms SNPs) in TLR2 and 6 SNPs in TLR4 and susceptibility to $H$. pylori-related gastrointestinal diseases in Japanese subjects.

\section{Methodology}

\subsection{Subjects}

This study protocol was approved by the Ethics Committee of Tokai University Hospital, Kanagawa, Japan. Written informed consent was obtained from all individuals prior to enrolling them in the study, according to the ethical guidelines of the Declaration of Helsinki. A total of 100 patients with histologically diagnosed gastric cancer (male: 79 cases, age: $72.3 \pm 8.2$ y [mean $\pm \mathrm{SD}$ ]), 105 patients with gastric ulcer (male: 71 cases, age: 66.3 $\pm 13.6 \mathrm{y}$ ), 102 patients with atrophic gastritis (male: 41 cases, age: $69.6 \pm 9.4 \mathrm{y}$ ), and 72 patients with duodenal ulcer (male: 51 cases, age: $59.0 \pm 14.7$ y) were recruited at Tokai University Hospital. The cancer-free control group comprising individuals with no previous history of gastric disease, was composed of 428 healthy individuals (male: 255 cases, age: $48.4 \pm 13.12$ y), recruited at Tokai University School of Medicine.

\subsection{Determination of TLR2 and TLR4 Genotypes}

Peripheral blood samples were obtained from all subjects and genomic DNA was subsequently extracted from the samples using a DNA extraction kit (Takara, Otsu, Japan).We selected tagging SNPs covering theTLR2 and TLR4 regions, using the HapMap Japanese data set (MAF $\geq 5 \%$, pairwiser ${ }^{2} \geq 0.8$, PHWE $\geq 0.05$ ). In addition, we selected non-synonymous SNPs that had previously been reported to be associated with other diseases. A 
TaqMan 5' exonuclease assay was used to genotype 7 SNPs in TLR2 and 6 SNPs in TLR4 with primers supplied by Applied Biosystems (Foster City, CA, USA), following the manufacturer's instructions. The fluorescence signal of the probes was detected using a 755 Real-Time PCR System (Applied Biosystems). 7 SNPs in TLR2 and 6 SNPs in TLR4 were genotyped in a total of 379 patients and controls.

\subsection{Statistical Analysis}

Differences in allele and genotype frequencies among the patients with either of $4 \mathrm{H}$. pylori-related gastroduodenal diseases and the controls were assessed by chi-square tests. The chi-square test was also used for determining Hardy-Weinberg equilibrium. Continuous variables were calculated as the mean \pm standard deviation (SD). Genotype and allele frequencies were analyzed using logistic regression models adjusted for age and gender. Odds ratios (ORs) were calculated using a dominant model (i.e., combining heterozygous and homozygous for the minor allele) for all polymorphisms. Differences in continuous variables were analyzed using the Mann-Whitney $U$-test. Statistical analyses were performed using the Stat Flex (version 6.0) computer program. The criterion for statistical significance was a p-value of $<0.05$.

\section{Results}

The genotype and allele frequency distributions of 9 polymorphisms were found to be in Hardy-Weinberg equilibrium, in both control and gastroduodenal disease groups (data not shown). TLR2 rs5743704, TLR2 rs5743708, TLR4 rs4986790, and TLR4 rs4986791 polymorphisms were not informative (heterozygous) in either control or patient groups.

The genotype and allele frequencies of the 9 informative polymorphisms and OR values of gastroduodenal disease patients and the control groups, adjusted for age and gender, are shown in Table 1. The frequencies of TLR4 rs10759932 TC and CC genotypes in patients with gastric cancer were lower than those in the control group; however, this difference infrequencies failed to reach significance $(p=0.059$, OR: $0.52,95 \%$ confidence interval $[\mathrm{CI}]: 0.26-1.02)$. As shown in Table 1 , significant differences were found when comparing the other genotype or allele frequencies of TLR2 and TLR4 polymorphisms between patients with gastric cancer and controls. No significant association was detected between the genotype or allele frequencies of polymorphisms in TLR2 or TLR4 and the risk of gastric ulcer, duodenal ulcer, or atrophic gastritis.

\section{Discussion}

Responses to TLR ligands may be altered by SNPs in TLR encoding genes, resulting invariable susceptibility to H. pylori-related gastrointestinal diseases after long-term infection. Therefore, an investigation of the association between polymorphisms in TLR2 and TLR4 and the risks of $H$. pylori-related gastrointestinal diseases is of value. This study involved an exhaustive genetic analysis, exploring the association between SNPs in TLR2 and TLR4 and susceptibility to $H$. pylori-related gastroduodenal diseases, including gastric cancer.

Previous studies focused only on 1 or 2 SNPs in these genes, which may not have been adequate for determining their potential effects on susceptibility to gastroduodenal diseases. The SNPs most intensively investigated in TLR4 are rs4986790 and rs4986791, which had been shown to be associated with susceptibility to gastric cancer in Caucasian, Brazilian, and Indian populations [10] [19] [20]. However, neither of these polymorphisms was found to be informative in this or in other Asian study populations [17] [21]. Thus, these polymorphisms may not be important factors in the development of gastric cancer in some Asian countries. Therefore, other TLR4 polymorphisms were investigated in the present study.

We found weak association between a polymorphism in the 5'-flanking region of TLR4 (rs10759932) and the risk of gastric cancer; however, this association failed to reach statistical significance. There have been only few studies that evaluated the association between this TLR4 polymorphism and the risks of gastrointestinal diseases. In a recent Chinese study, Fan et al. reported that TLR4 rs10759932 TC and CC genotypes were associated with a lower risk of developing precancerous lesions of the stomach [22]. Furthermore, Huang et al. found that these TC/CC rs 10759932 genotypes in TLR4 were associated with a significantly reduced risk of gastric cancer in a Chinese population [23]. It has been hypothesized that this polymorphism in the 5'-flanking region of TLR4 may influence the expression of TLR4 mRNA, and may result in changing the inflammatory response in the 
Table 1. Genotype and allele frequencies of TLR2 and TLR4 polymorphisms adjusted for age, gender in gastric cancer, gastric ulcer, atrophic gastritis, duodenal ulcer, and control groups.

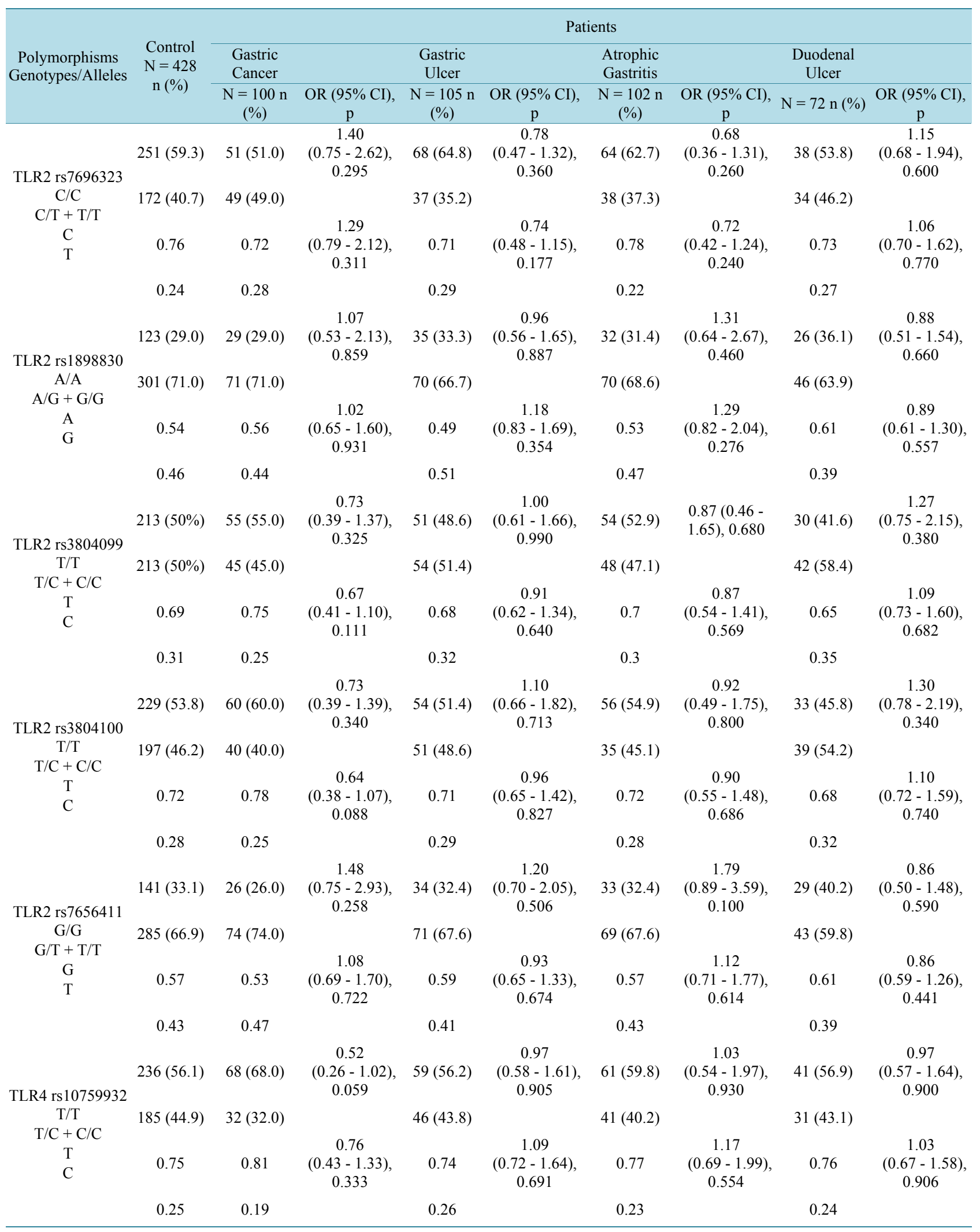




\begin{tabular}{|c|c|c|c|c|c|c|c|c|c|}
\hline \multicolumn{10}{|l|}{ Continued } \\
\hline \multirow{4}{*}{$\begin{array}{c}\text { TLR4 rs1927911 } \\
\text { G/G } \\
\text { G/A }+\mathrm{A} / \mathrm{A} \\
\mathrm{G} \\
\mathrm{A}\end{array}$} & $174(40.9)$ & $50(50.0)$ & $\begin{array}{c}0.91 \\
(0.48-1.70), \\
0.758\end{array}$ & $44(41.9)$ & $\begin{array}{c}1.26 \\
(0.75-2.12) \\
0.373\end{array}$ & $48(47.1)$ & $\begin{array}{c}1.43 \\
(0.75-2.75) \\
0.270\end{array}$ & $\begin{array}{c}27 \\
(37.5)\end{array}$ & $\begin{array}{c}1.42 \\
(0.82-2.44), \\
0.210\end{array}$ \\
\hline & $251(59.1)$ & $50(50.0)$ & & $61(58.1)$ & & $54(52.9)$ & & $45(62.5)$ & \\
\hline & 0.64 & 0.7 & $\begin{array}{c}0.95 \\
(0.59-1.52), \\
0.820\end{array}$ & 0.66 & $\begin{array}{c}1.08 \\
(0.75-1.57) \\
0.678\end{array}$ & 0.69 & $\begin{array}{c}1.16 \\
(0.72-1.88) \\
0.537\end{array}$ & 0.6 & $\begin{array}{c}1.28 \\
(0.88-1.88), \\
0.197\end{array}$ \\
\hline & 0.36 & 0.3 & & 0.34 & & 0.31 & & 0.4 & \\
\hline \multirow{4}{*}{$\begin{array}{c}\text { TLR4 rs11536889 } \\
\text { G/G } \\
\text { G/C }+\mathrm{C} / \mathrm{C} \\
\mathrm{G} \\
\mathrm{C}\end{array}$} & $243(57.2)$ & $53(53.0)$ & $\begin{array}{c}1.02 \\
(0.54-1.92), \\
0.952\end{array}$ & $64(61.0)$ & $\begin{array}{c}0.77 \\
(0.46-1.30) \\
0.329\end{array}$ & $55(53.9)$ & $\begin{array}{c}0.75 \\
(0.39-1.43) \\
0.390\end{array}$ & $47(65.2)$ & $\begin{array}{c}0.66 \\
(0.38-1.14), \\
0.130\end{array}$ \\
\hline & $182(42.8)$ & $47(47.0)$ & & $41(39.0)$ & & $47(46.1)$ & & $25(34.8)$ & \\
\hline & 0.75 & 0.74 & $\begin{array}{c}0.97 \\
(0.58-1.61), \\
0.905\end{array}$ & 0.79 & $\begin{array}{c}0.80 \\
(0.52-1.23) \\
0.309\end{array}$ & 0.75 & $\begin{array}{c}0.82 \\
(0.48-1.38) \\
0.447\end{array}$ & 0.81 & $\begin{array}{c}0.67 \\
(0.42-1.07), \\
0.095\end{array}$ \\
\hline & 0.25 & 0.26 & & 0.21 & & 0.25 & & 0.19 & \\
\hline \multirow{4}{*}{$\begin{array}{c}\text { TLR4 rs7037117 } \\
\text { A/A } \\
\mathrm{A} / \mathrm{G}+\mathrm{G} / \mathrm{G} \\
\mathrm{A} \\
\mathrm{G}\end{array}$} & $269(63.3)$ & $63(63.0)$ & $\begin{array}{c}1.33 \\
(0.69-2.56), \\
0.390\end{array}$ & $66(62.9)$ & $\begin{array}{c}1.25 \\
(0.74-2.09) \\
0.407\end{array}$ & $68(66.7)$ & $\begin{array}{c}1.22 \\
(0.62-2.38) \\
0.570\end{array}$ & $41(56.9)$ & $\begin{array}{c}1.49 \\
(0.87-2.54), \\
0.150\end{array}$ \\
\hline & $156(36.7)$ & $37(37.0)$ & & $39(37.1)$ & & $34(33.3)$ & & $31(43.1)$ & \\
\hline & 0.8 & 0.8 & $\begin{array}{c}1.29 \\
(0.74-2.23), \\
0.371\end{array}$ & 0.8 & $\begin{array}{c}1.18 \\
(0.76-1.83) \\
0.456\end{array}$ & 0.83 & $\begin{array}{c}1.12 \\
(0.63-1.99) \\
0.710\end{array}$ & 0.76 & $\begin{array}{c}1.38 \\
(0.89-2.14), \\
0.152\end{array}$ \\
\hline & 0.2 & 0.2 & & 0.2 & & 0.17 & & 0.24 & \\
\hline
\end{tabular}

stomach. The increased TLR activity may then modulate the development of gastric cancer. Since the possibility that TLR4 may be involved in the development of gastric cancer cannot be ruled out in the Japanese population, further studies employing a larger number of subjects are necessary.

Achyut et al. [18] found a correlation between gastric atrophy and TLR4 rs4986791. Since the polymorphism was not informative in this or other Asian study populations, it may not be an important factor in the development of gastric atrophy in these populations. Hishida et al. [24] reported that the TLR4 rs11536889 G/C polymorphism was a risk factor for severe gastric atrophy in Japanese subjects. However, our data did not indicate that any TLR4 polymorphism was associated with gastric atrophy. This may be because the association found by Hishida et al. involved severe gastric atrophy, which was graded from none to severe according to serum levels of pepsinogens. Future studies will be needed to verify these findings.

A 22-bp insertion/deletion polymorphism, known as TLR2 -196 to -174 deletion, has been reported to influence the transcription activity of TLR2. Recent evidence has suggested that this polymorphism is associated with a variety of cancers, such as gastric cancer, prostate cancer, cervical cancer, and so on [15] [16] [25] [26]. However, to date there has been little information about the association between gastric cancer and any other polymorphisms in TLR2. Although we investigated 7 SNPs in TLR2 in this study, no evidence was found indicating that these SNPs played roles in the 4 H. pylori-related gastroduodenal diseases.

The present study had several limitations. The H. pylori status of participants was not examined and we could not investigate the association between polymorphisms in TLR2 or TLR4 and gastric atrophy in more detail, because of a lack of serum samples.

In conclusion, this study revealed that SNPs in TLR2 and TLR4 may not be associated with the development of $H$. pylori-related gastroduodenal diseases, and did not reproduce the previous noted association between gastric cancer and TLR4 polymorphisms in the Japanese population. However, weak association was found between a polymorphism in the 5'-flanking region of TLR4 (rs10759932) and the risk of gastric cancer. Since it remains possible that TLR4 signaling pathways can play a role in the development of gastric cancer, further well-designed, comprehensive studies, employing a larger number of subjects, are necessary to verify our findings.

\section{Conflict of Interest}

The authors declare no conflicts of interest. 


\section{References}

[1] Blaser, M.J. and Atherton, J.C. (2004) Helicobacter pylori Persistence: Biology and Disease. Journal of Clinical Investigation, 113, 321-333. http://dx.doi.org/10.1172/JCI20925

[2] El-Omar, E.M., Rabkin, C.S., Gammon, M.D., et al. (2003) Increased Risk of Noncardia Gastric Cancer Associated with Proinflammatory Cytokine Gene Polymorphisms. Gastroenterology, 125, 364-371.

[3] Parkin, D.M., Pisani, P. and Ferlay, J. (1999) Estimates of the Worldwide Incidence of 25 Major Cancers in 1990. International Journal of Cancer, 80, 827-841. http://dx.doi.org/10.1002/(SICI)1097-0215(19990315)80:6<827::AID-IJC6>3.0.CO;2-P

[4] Peek Jr., R.M. and Blaser, M.J. (2002) Helicobacter pylori and Gastrointestinal Tract Adenocarcinomas. Nature Reviews Cancer, 2, 28-37. http://dx.doi.org/10.1038/nrc703

[5] Uemura, N., Okamoto, S., Yamamoto, S., et al. (2001) Helicobacter pylori Infection and the Development of Gastric Cancer. The New England Journal of Medicine, 345, 784-789. http://dx.doi.org/10.1056/NEJMoa001999

[6] Barton, G.M. and Kagan, J.C. (2009) A Cell Biological View of Toll-Like Receptor Function: Regulation through Compartmentalization. Nature Reviews Immunology, 9, 535-542. http://dx.doi.org/10.1038/nri2587

[7] Schmausser, B., Andrulis, M., Endrich, S., et al. (2004) Expression and Subcellular Distribution of Toll-Like Receptors TLR4, TLR5 and TLR9 on the Gastric Epithelium in Helicobacter pylori Infection. Clinical and Experimental Immunology, 136, 521-526. http://dx.doi.org/10.1111/j.1365-2249.2004.02464.x

[8] Torok, A.M., Bouton, A.H. and Goldberg, J.B. (2005) Helicobacter pylori Induces Interleukin-8 Secretion by TollLike Receptor 2 and Toll-Like Receptor 5-Dependent and -Independent Pathways. Infection and Immunity, 73, 15231531. http://dx.doi.org/10.1128/IAI.73.3.1523-1531.2005

[9] Chang, Y.J., Wu, M.S., Lin, J.T., et al. (2005) Helicobacter pylori-Induced Invasion and Angiogenesis of Gastric Cells Is Mediated by Cyclooxygenase-2 Induction through TLR2/TLR9 and Promoter Regulation. Journal of Immunology, 175, 8242-5252. http://dx.doi.org/10.4049/jimmunol.175.12.8242

[10] Schmausse, B., Andrulis, M., Endrich, S., et al. (2004) Expression and Subcellular Distribution of Toll-Like Receptors TLR4, TLR5 and TLR9 on the Gastric Epithelium in Helicobacter pylori Infection. Clinical and Experimental Immunology, 136, 521-526. http://dx.doi.org/10.1111/j.1365-2249.2004.02464.x

[11] Pimentel-Nunes, P., Afonso, L., Lopes, P., Roncon-Albuquerque Jr., R., Gonçalves, N., Henrique, R., et al. (2011) Increased Expression of Toll-Like Receptors (TLR) 2, 4 and 5 in Gastric Dysplasia. Pathology \& Oncology Research, 17, 677-683.

[12] Smith Jr., M.F., Mitchell, A., Li, G., Ding, S., Marie Fitzmaurice, A., Ryan, K., Crowe, S. and Goldberg, J.B. (2003) Toll-Like Receptor (TLR) 2 and TLR5, but Not TLR4, Are Required for Helicobacter pylori-Induced NF- $\kappa$ B Activation and Chemokine Expression by Epithelial Cells. Journal of Biological Chemistry, 278, 32552-32560. http://dx.doi.org/10.1074/jbc.M305536200

[13] Srivastava, K., Srivastava, A., Kumar, A. and Mittal, B. (2010) Significant Association between Toll-Like Receptor Gene Polymorphisms and Gallbladder Cancer. Liver International, 30, 1067-1072.

[14] Slattery, M.L., Herrick, J.S., Bondurant, K.L. and Wolff, R.K. (2012) Toll-Like Receptor Genes and Their Association with Colon and Rectal Cancer Development and Prognosis. International Journal of Cancer, 130, 2974-2980. http://dx.doi.org/10.1002/ijc.26314

[15] Pandey, S., Mittal, R.D., Srivastava, M., Srivastava, K., Singh, S., Srivastava, S. and Mittal, B. (2009) Impact of TollLike Receptors TLR2 (-196 to -174 Del) and TLR4 (Asp299Gly, Thr399Ile) in Cervical Cancer Susceptibility in North Indian Women. Gynecologic Oncology, 114, 501-505. http://dx.doi.org/10.1016/j.ygyno.2009.05.032

[16] Tahara, T., Arisawa, T., Wang, F., Shibata, T., Nakamura, M., Sakata, M., et al. (2007) Toll-Like Receptor 2 -196 to 174 Del Polymorphism Influences the Susceptibility of Japanese People to Gastric Cancer. Cancer Science, 98, 17901794. http://dx.doi.org/10.1111/j.1349-7006.2007.00590.x

[17] Wu, M.S., Cheng, T.Y., Shun, C.T., Lin, M.T., Chen, L.C. and Lin, J.T. (2006) Functional Polymorphisms of CD14 and Toll-Like Receptor 4 in Taiwanese Chinese with Helicobacter pylori Related Gastric Malignancies. Hepato-Gastroenterology, 53, 807-810.

[18] Achyut, B.R., Ghoshal, U.C., Moorchung, N. and Mittal, B. (2007) Association of Toll-Like Receptor-4 (Asp299Gly and Thr399Ileu) Gene Polymorphisms with Gastritis and Precancerous Lesions. Human Immunology, 68, 901-907. http://dx.doi.org/10.1016/j.humimm.2007.10.006

[19] de Oliveira, J.G. and Silva, A.E. (2012) Polymorphisms of the TLR2 and TLR4 Genes Are Associated with Risk of Gastric Cancer in a Brazilian Population. World Journal of Gastroenterology, 18, 1235-1242. http://dx.doi.org/10.3748/wig.v18.i11.1235

[20] Hold, G.L., Rabkin, C.S., Chow, W.H., Smith, M.G., Gammon, M.D., Risch, H.A., et al. (2007) A Functional Poly- 
morphism of Toll-Like Receptor 4 Gene Increases Risk of Gastric Carcinoma and Its Precursors. Gastroenterology, 132, 905-912. http://dx.doi.org/10.1053/j.gastro.2006.12.026

[21] Tahara, T., Arisawa, T., Shibata, T., Hirata, I. and Nakano, H. (2007) Absence of Common Polymorphisms of Toll Like Receptor 4 (TLR4): Asp299Gly, Thr399Ile in Patients with Gastroduodenal Diseases in Japan. Journal of Clinical Biochemistry and Nutrition, 40, 62-65. http://dx.doi.org/10.3164/jcbn.40.62

[22] Fan, Y.F., Wu, Y.M., Liu, H., Yu, Y., Jiang, Y.Y., Xue, Y.Z., et al. (2014) TLR4 Polymorphisms Associated with Developing Gastric Pre-Cancer Lesions in a Chinese Han Population. Human Immunology, 75, 176-181. http://dx.doi.org/10.1016/j.humimm.2013.11.002

[23] Huang, H., Wu, J., Jin, G., Zhang, H.Z., Ding, Y.B., Hua, Z.L., et al. (2010) A 5'-Flanking Region Polymorphism in Toll-Like Receptor 4 Is Associated with Gastric Cancer in a Chinese Population. Journal of Biomedical Research, 24, 100-106. http://dx.doi.org/10.1016/S1674-8301(10)60017-6

[24] Hishida, A., Matsuo, K., Goto, Y., Mitsuda, Y., Hiraki, A., Naito, M., et al. (2009) Toll-Like Receptor 4 +3725 G/C Polymorphism, Helicobacter pylori Seropositivity, and the Risk of Gastric Atrophy and Gastric Cancer in Japanese. Helicobacter, 14, 47-53. http://dx.doi.org/10.1111/j.1523-5378.2009.00659.x

[25] Zeng, H.M., Zhang, Y., Zhang, L., Ma, J.L., Zhou, T., Su, H.J., et al. (2011) Genetic Variants of Toll-Like Receptor 2 and 5, Helicobacter pylori Infection, and Risk of Gastric Cancer and Its Precursors in a Chinese Population. Cancer Epidemiology, Biomarkers \& Prevention, 20, 2594-2602. http://dx.doi.org/10.1158/1055-9965.EPI-11-0702

[26] Mandal, R.K., George, G.P. and Mittal, R.D. (2012) Association of Toll-Like Receptor (TLR) 2, 3 and 9 Genes Polymorphism with Prostate Cancer Risk in North Indian Population. Molecular Biology Reports, 39, 7263-7269. http://dx.doi.org/10.1007/s11033-012-1556-5 
Scientific Research Publishing (SCIRP) is one of the largest Open Access journal publishers. It is currently publishing more than 200 open access, online, peer-reviewed journals covering a wide range of academic disciplines. SCIRP serves the worldwide academic communities and contributes to the progress and application of science with its publication.

Other selected journals from SCIRP are listed as below. Submit your manuscript to us via either submit@scirp.org or Online Submission Portal.
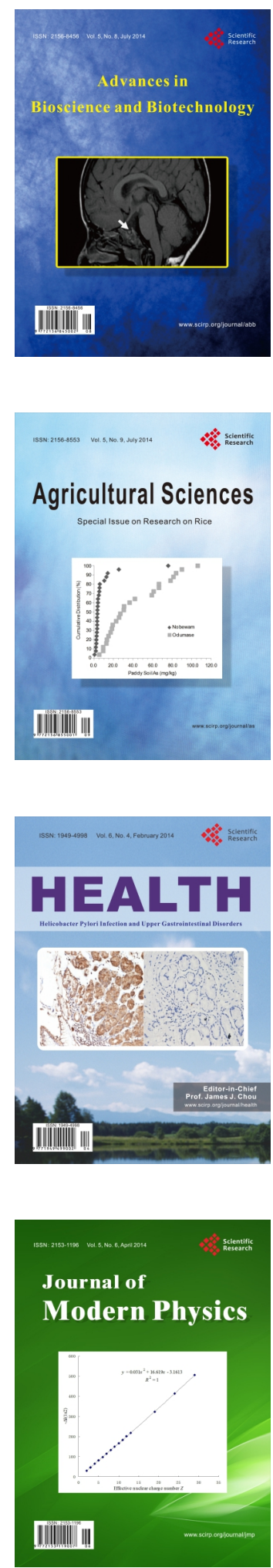
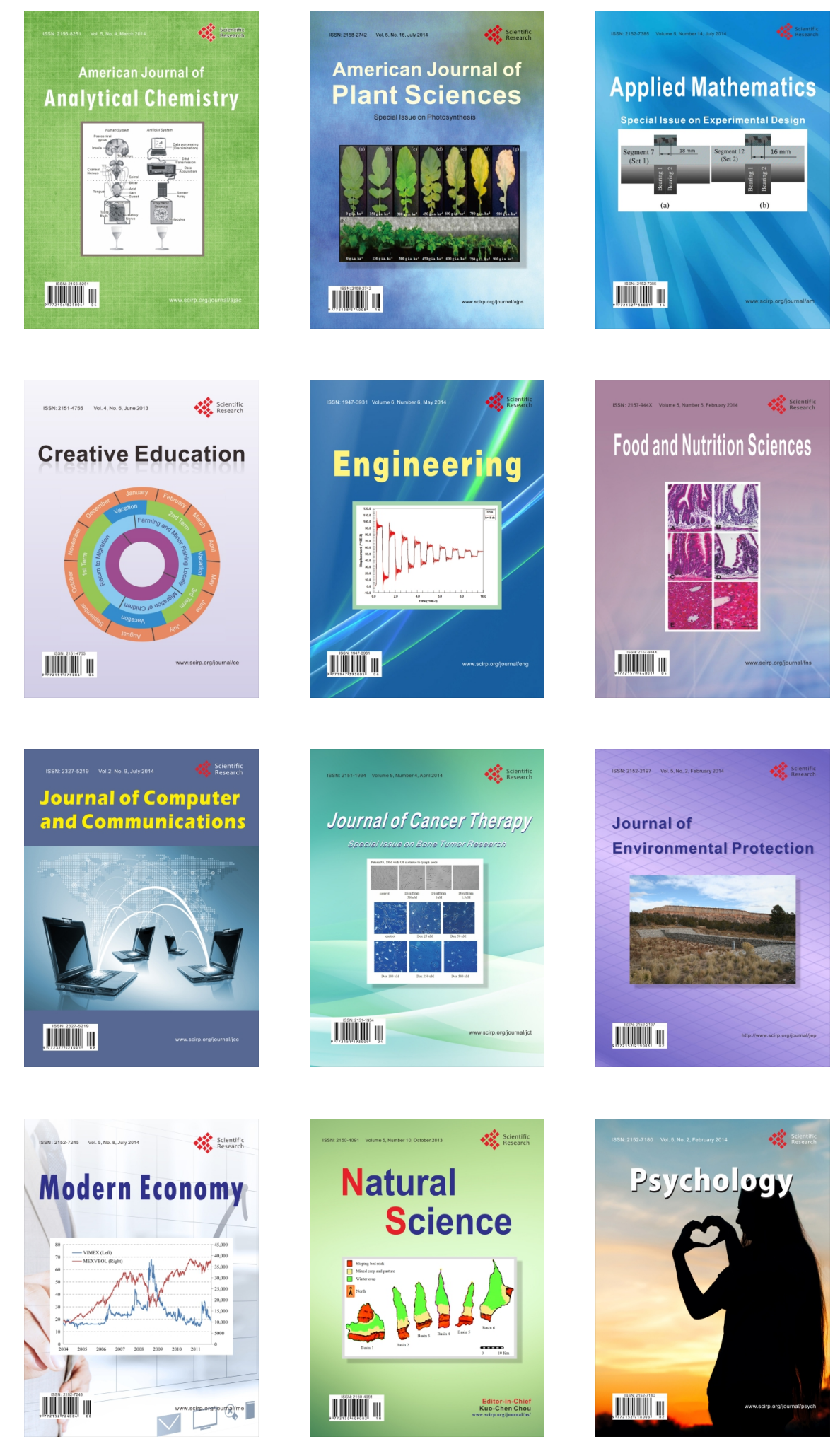